\title{
Prevalence of Schistosomiasis in a neglected community, South western Nigeria at two points in time, spaced three years apart
}

\author{
Oluchi G Otuneme ${ }^{1}$, Oluwasola O Obebe ${ }^{2}$, Titus T Sajobi ${ }^{3}$, Waheed A Akinleye ${ }^{1}$, Taiwo G Faloye ${ }^{1}$
}

1. Department of Medical Laboratory Science, Babcock University, Ilishan Remo, Ogun State, Nigeria.

2. Department of Veterinary Parasitology \& Entomology, University of Ibadan, Oyo State, Nigeria.

3. Department of Public Health, Babcock University, Ilishan Remo, Ogun State, Nigeria.

\begin{abstract}
Background: In recent years, the prevalence of schistosomiasis, a neglected tropical infection, has increased in underprivileged rural communities characterized by poverty.

Objective: This cross-sectional community-based study was carried out to determine the prevalence of urinary schistosomiasis in a neglected community of Apojola community, South-Western Nigeria at two points in time, spaced three years apart

Method and results: A total of 145 participants were screened and 44.1\% were diagnosed to have urinary Schistosoma haematobium infection after sedimentation and microscopy. The prevalence of schistosomiasis among females was higher (45.3\%) than that among males $(42.4 \%)$ but not significantly different $(0.723)$. The prevalence of participants with light infection $(26 \%)$ was significantly higher than those with heavy infection (11.0\%). The predisposing factors with statistically significant association with Schistosoma haematobium infection were age (0.000), level of education (0.002), eating/selling of snails (0.037), occupation (0.000), drinking water (0.001), swimming (0.008), and washing in a river (0.019).

Conclusion: These findings indicate that the study area is still endemic to urinary schistosomiasis after three years of research and school-age children and teenagers are the populations at risk of urinary schistosomiasis. Community health education on the cause, mode of transmission, prevention, and prompt treatment of schistosomiasis is recommended.
\end{abstract}

Keywords: Urinary Schistosomiasis, neglected community, Nigeria.

DOI: https://dx.doi.org/10.4314/ahs.v19i1.5

Cite as: Otuneme OG, Obebe OO, Sajobi TT, Akinleye WA, Faloye TG. Prevalence of Schistosomiasis in a neglected community, South western Nigeria at two points in time, spaced three years apart. Afri Health Sci. 2019;19(1): 1338-1345. https:// dx.doi.org/10.4314/abs.v19i1.5

\section{Introduction}

Schistosoma haematobium infection is known worldwide as an important chronic and debilitating disease mainly affecting underprivileged rural Communities characterized by poverty, poor sanitation and hygiene ${ }^{1,2}$.

Schistosomiasis is one of the occupational associated infection that can be transmitted to a susceptible host or through recreation that involves contact with water infested with the free living cercariae that penetrate the skin and develops to maturity in the human ${ }^{3,4}$. Other probable

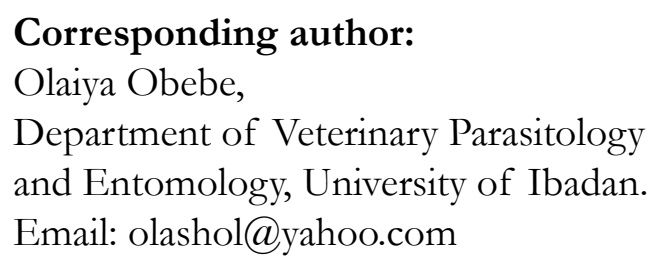

factors that influence transmission include environmental factors, water development schemes and people migration $^{3}$.

Schistosomiasis has been effectively controlled in many countries but its burden remains high especially in sub Saharan Africa including Nigeria. ${ }^{4,5,3}$

In Nigeria, the burden of Schistosomiasis is enormous with an estimate of 101.3 million people at risk $^{6-9}$. The huge burden has been associated with water resources and development schemes such as irrigation projects, rice/fish farming and dams ${ }^{10,11}$.

Chemotherapy, water, sanitation and hygiene, education and behaviour change programs; and occasionally, snail control has been suggested as an important aspect of schistosomiasis control programmes ${ }^{12}$. However, a better understanding of prevalence and risk factors for schisto- 
somiasis is important in controlling the disease. The high prevalence of urinary schistosomiasis obtained from Apojola community 3 years ago justified the need to assess the extent of control measures. As at the time of visit, Apojola still lack basic amenities such as sanitation facilities, a non-functional water borehole, good roads, health centre and electric power distribution. The present study was designed to determine the prevalence of schistosomiasis in a neglected community of Apojola, south-western Nigeria at two points in time, spaced three years apart

\section{Study area}

This study was 'conducted between May and July 2017 in Apojola community located around Oyan dam reservoir in Abeokuta North local Government Area, Ogun State,
Nigeria. Oyan river is located $07^{\circ} 58^{\prime} \mathrm{N}$ and $03^{\circ} 02^{\prime} \mathrm{E}$ with a catchments area of $1610 \mathrm{~km}^{2}$. The reservoir has a length of $27 \mathrm{~km}$ with a maximum width of $67 \mathrm{~km}$.and was primarily built to provide hydroelectric power and provide water for domestic and industrial uses. It also meant to supply water for an irrigated project of about 3,000 ha as well as provide fishing ground for the adjoining communities. Inhabitants are immigrant fishermen, a mixture of Moslem Hausas and Christian Idomas (figure 1)

Ethical, recruitment, enrolment and sample collection

Before the beginning of the study, the objectives and plan were explained to the village authorities to get their

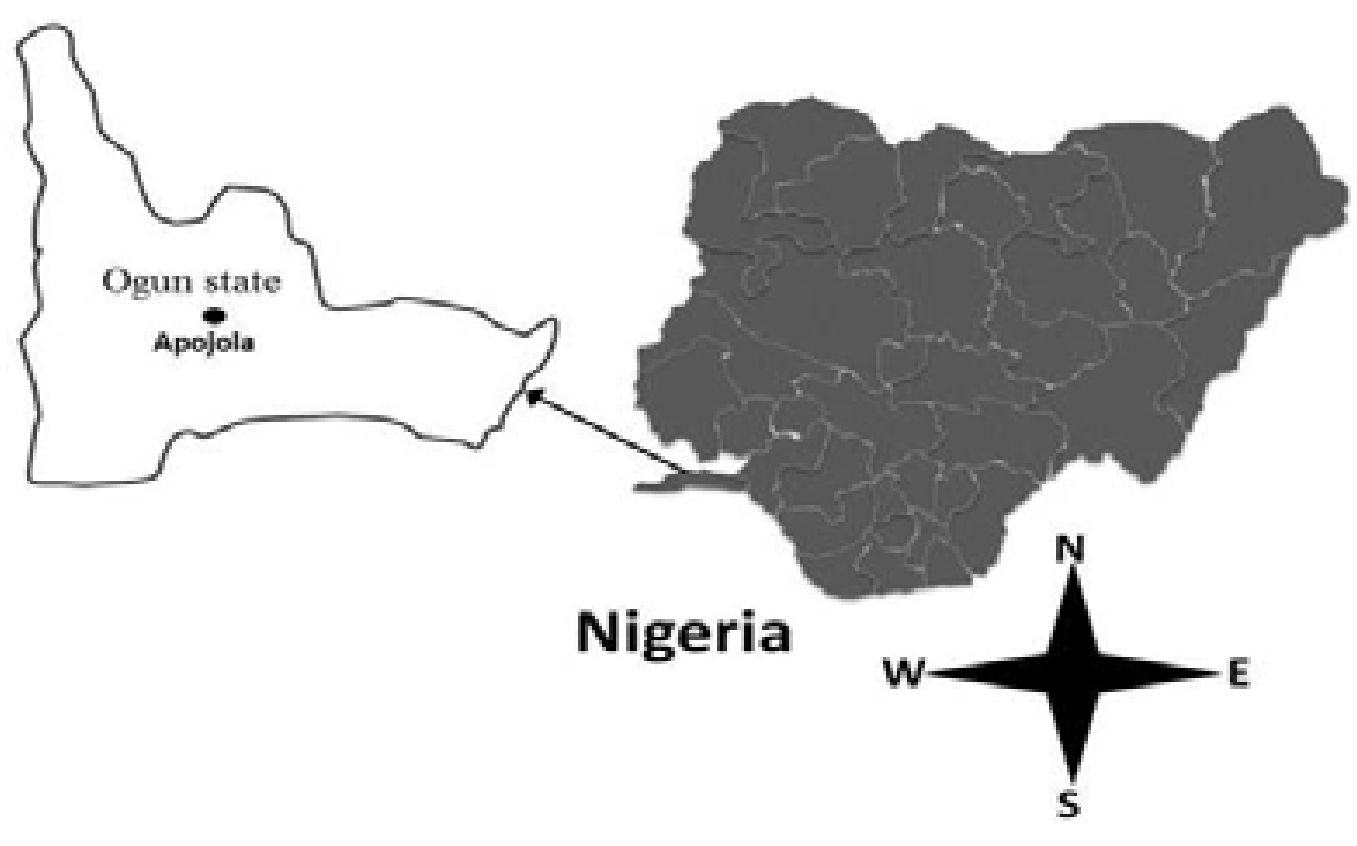

Figure 1: Map showing the sampling sites in South-western Nigeria

cooperation and permission to conduct the survey. The heads informed all the residents to gather at the village square where they received explanation about the objectives of the survey, benefits and their involvement. A total of 181 participants gathered at the village square and only 145 adults who agreed voluntarily to participate and children with parental consent were included in the study. They received labelled containers and were instructed to bring urine samples. Structured questionnaire was administered to each participant to obtain socio-demo- graphic, sanitation and water hygiene information which was then analysed to determine associated risk factors to Schistosoma infection. The protocol for this study followed ethical procedures/guidelines and was approved by the Olabisi Onabanjo University Teaching Hospital, Sagamu (OOUTH) research ethics committee with protocol no OOUTH/HREC/57/2016.

\section{Parasitological procedures}

Urine samples were stored in closed containers using ice park and transported to the laboratory to determine the prevalence and intensity of $S$. baematobium infection. In 
the laboratory, $10 \mathrm{ml}$ of each urine sample was centrifuged at $5000 \mathrm{rpm}$ for $5 \mathrm{~min}$. The supernatant was discarded to leave the sediment, which was placed on aclean glass slide and covered with a coverslip. These slides were observed microscopically using $\mathrm{x} 40$ objective lens for the presence of terminal-spined ova of eggs of S. haematobium. A positive sample was indicated by the presence of ova of $S$. haematobium and expressed as number of eggs $/ 10 \mathrm{ml}$ of urine $^{13}$, and the intensity of infection was graded as heavy (> $50 \mathrm{EP} 10 \mathrm{~mL})$, moderate $(10-49 \mathrm{EP} 10 \mathrm{~mL})$ and light (1-9 EP10 mL). A negative sample was indicated by the absence of parasite eggs ${ }^{13}$.

\section{Data analysis}

Data entry and analysis were carried out using SPSS version 18.0 (SPSS Inc., Chicago, IL, USA). Appropriate univariate and bivariate statistics were employed. Frequency tables and percentages were used to display categorical data. The Chi square was used to compare categorical data. Statistical significance was determined at the level of $\mathrm{p}<0.05$.

\section{Sociodemographic characteristics of study partici-} pants

A total of 145 urine samples were collected and analysed for urinary Schistosomiasis. The characteristics of the study participants are shown in Table 1 . The age range of the study participants was (5-59 years). Of the 145 participants, $59.3 \%$ (86/145) were female and 40.7\% (59/145) were male, giving a gender ratio of 1.46: 1 (females: males). The majority $(55.2 \%)$ of the participants were of the age range $5-15 y$ ears (figure 2). $68.3 \%$ of the study participants had primary school education and $58.6 \%$ of the participants are students (Table 1)

Prevalence of schistosoma haematobium

The overall prevalence of Schistosoma haematobium infection in the study population is $44.1 \%$. Urinary schistosomiasis was more prevalent among females (45.3\%; 39/86)

\section{Table 1: Socio-demographic characteristics of participants in a neglected community, Nigeria}

\begin{tabular}{lcc}
\hline Variables & Frequency & $\%$ \\
\hline Age (years) & & \\
$5-15$ & 80 & 55.2 \\
$16-26$ & 16 & 11.0 \\
$27-37$ & 20 & 13.8 \\
$38-48$ & 16 & 11.0 \\
$49-59$ & 13 & 8.9 \\
Gender & & \\
Male & 59 & 40.7 \\
Female & 86 & 59.3 \\
Education & & \\
None & 19 & 13.1 \\
Primary & 99 & 68.3 \\
Secondary & 25 & 17.2 \\
Graduate & 2 & 1.4 \\
Occupation & & \\
Farming & 35 & 24.1 \\
Housewife & 11 & 7.6 \\
Student & 85 & 58.6 \\
Trading & 14 & 9.7 \\
\hline
\end{tabular}




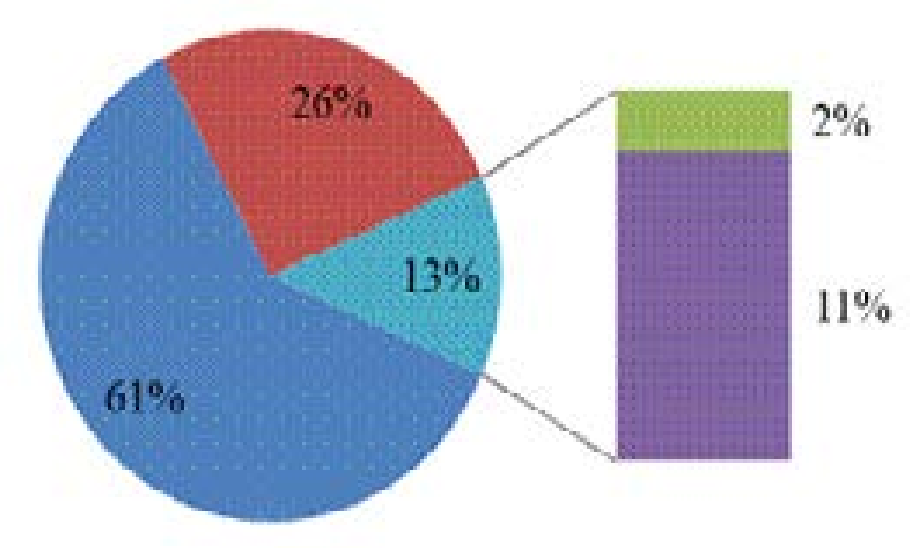

$\|$ Negative $\|$ Light infection $=$ Moderate infection $\|$ Heavy infection

Figure 2: intensity of Schistosoma haematobium infection among participants

than in males $(42.4 \% ; 25 / 59)$. However, there was no significant different between Schistosomiasis and gender (0.723). There was an association between Schistosoma baematobium infection and variable such as age (0.000), level of education (0.002), eating/selling of snails (0.037), occupation (0.000), drinking water (0.001), swimming (0.008), and washing in river (0.019) (Table 2)

Intensity of Schistosoma haematobium

The intensity of infection of participants is shown in Figure 2. Light, moderate and heavy infections were detected in the study using centrifugation method for the egg 
Table 2: Factors influencing Schistosoma haematobium infection in

a neglected community, Nigeria

\begin{tabular}{|c|c|c|c|c|}
\hline Factor & Subcategory & $\begin{array}{l}\text { S. haematobium } \\
\text { No. negative }\end{array}$ & $\begin{array}{l}\text { Status } \\
\text { No. Positive }\end{array}$ & $p$ value \\
\hline Gender & $\begin{array}{c}\text { Male } \\
\text { Female }\end{array}$ & $\begin{array}{l}34 \\
47\end{array}$ & $\begin{array}{l}25(42.4) \\
39(45.3)\end{array}$ & 0.723 \\
\hline Age & $\begin{array}{c}5-15 \\
16-26 \\
27-37 \\
38-48 \\
49-59\end{array}$ & $\begin{array}{l}28 \\
12 \\
16 \\
14 \\
11\end{array}$ & $\begin{array}{l}52(65.0) \\
4(25.0) \\
4(20.0) \\
2(12.5) \\
2(15.4)\end{array}$ & 0.000 \\
\hline Level of education & $\begin{array}{c}\text { None } \\
\text { Primary } \\
\text { Secondary } \\
\text { Graduate }\end{array}$ & $\begin{array}{c}16 \\
45 \\
18 \\
2\end{array}$ & $\begin{array}{l}3(15.8) \\
54(54.5) \\
7(28.0) \\
0(0.0)\end{array}$ & 0.002 \\
\hline Occupation & $\begin{array}{l}\text { Farming } \\
\text { Housewife } \\
\text { Student } \\
\text { Trading }\end{array}$ & $\begin{array}{l}28 \\
10 \\
30 \\
13\end{array}$ & $\begin{array}{l}7(20.0) \\
1(9.1) \\
55(64.7) \\
1(7.1)\end{array}$ & 0.000 \\
\hline Sell/eating of snail & $\begin{array}{l}\text { Yes } \\
\text { No }\end{array}$ & $\begin{array}{l}39 \\
52\end{array}$ & $\begin{array}{l}34(53.9) \\
30(36.6)\end{array}$ & 0.037 \\
\hline Drinking water & $\begin{array}{c}\text { Sachet } \\
\text { Stream } \\
\text { Well }\end{array}$ & $\begin{array}{c}2 \\
64 \\
15\end{array}$ & $\begin{array}{l}2(50.0) \\
62(49.2) \\
0(0.0)\end{array}$ & 0.001 \\
\hline Swimming & $\begin{array}{l}\text { Yes } \\
\text { No }\end{array}$ & $\begin{array}{l}61 \\
20\end{array}$ & $\begin{array}{l}59(49.1) \\
5(20.0)\end{array}$ & 0.008 \\
\hline Washing in river & $\begin{array}{l}\text { Yes } \\
\text { No }\end{array}$ & $\begin{array}{l}65 \\
16\end{array}$ & $\begin{array}{l}60(48.0) \\
4(20.0)\end{array}$ & 0.019 \\
\hline
\end{tabular}

count. Of the 145 persons examined for urinary Schistosomiasis in the study area, $61 \%(\mathrm{n}=88)$ were found to be negative for the presence of Schistosoma haematobium egg, $2 \%(n=3)$ were excreting between 1-9eggs/10ml, 26\% $(\mathrm{n}=38)$ were excreting between $10-49 \mathrm{eggs} / 10 \mathrm{ml}$ urine, while $11.0 \%(\mathrm{n}=16)$ were excreting above $50 \mathrm{eggs} / 10 \mathrm{ml}$ urine.

\section{Discussion}

The study showed a high prevalence of Schistosoma baematobium infection among resident of Apojola community, Nigeria. Previous studies in Nigeria ${ }^{14-17}$ and other countries like Ghana ${ }^{18}$ and Cameroon ${ }^{19}$, reported a comparable prevalence of Schistosoma haematobium infection.
However, data from various parts of Nigeria ${ }^{20-22}$, showed lower prevalence than that obtained in the present study. Factors including poverty, ignorance, poor living conditions, inadequate sanitation and water supplies as well as deplorable personal and environmental hygiene characteristic of many rural communities have been suggested as reasons for variation in prevalence of infection ${ }^{23}$.

The frequency of infection was higher among the female participants compared to the male counterpart, although there was no statistical significance in the association. A study carried out in Nigeria found similar results ${ }^{24}$ while others reported the opposite ${ }^{25,26}$. The fact that fetching water and washing clothes are seen as female responsibilities in Nigeria, suggests the likely reason for Schistosoma 
haematobium infection preponderance among females. In the present study, prevalence was higher among schoolaged participants and the association was statistically significant. Previous studies reported higher infections among younger age group in Nigeria ${ }^{27}$, Malawi ${ }^{28}$ Camer$\operatorname{oon}^{29}$ and Cote d'Ivoire ${ }^{30}$. The higher prevalence among younger age group is not surprising. This is because this same group are the most commonly found in persistent and unrestrained water contact activities such as bathing and swimming. In addition, participants' levels of education and occupation showed a statistical association with urinary schistosomiasis. This is supported by the findings of some previous study that associated higher infections with different level of education and occupation ${ }^{31,32}$. The higher prevalence may be suggestive of their frequency of going to the river. In addition, the high illiteracy and neglect levels of the parents, observed in the study area, can lead to the non-education of preventive measures to their children, therefore influencing transmission pattern

Eating/selling of snails, using the stream as a source of drinking water, swimming, and washing in a river were significantly associated with Schistosoma haematobium infection. In accordance with our findings, previous studies reported similar observations ${ }^{9,33,28}$. Water contact activities and traditional agricultural practices such as washing, fishing, bathing, and farming may influence the transmission of the disease in many parts of Nigeria.

Furthermore, the prevalence of participants with light infection was significantly higher than those with heavy infection. The higher prevalence of light infection reported here was in accordance with findings of Uneke et al., ${ }^{34}$ an indication that the distribution of schistosomiasis in endemic communities fits a negative binomial curve, with most infected individuals harbouring low worm burdens and only a small proportion having heavy infections ${ }^{35}$. However, according to Secor et al., ${ }^{36}$, the aggregation of worm load in a small percentage of infected individuals may have various explanations including genetic vulnerability and the implication of these epidemiologic results are important to our understanding of the dynamics of the Schistosoma baematobium infection and its control in the populations studied.

We acknowledge some limitations of our methodology. This study had to rely on sedimentation method instead of the ideal filtration technique. In addition, our study was conducted on a smaller scale instead of the ideal larg- er scale. Thus, the prevalence rates of schistosomiasis are likely to be underestimated

\section{Conclusion}

The prevalence of $62 \% 0^{37}$ obtained 3 years ago compared with present $44.1 \%$ prevalence obtained in the study area shows that participants in Apojola community and its environ are still plagued with urinary Schistosomiasis. It seems that adequate control measures had not been deployed to this endemic zone of schistosomiasis. Therefore, there is an urgent need for Government to mount successful control interventions such as the provision of safe water supply, development of recreational water bodies to avoid contact with present infested water, control of snail vector, public awareness and education regarding urinary schistosomiasis in the area.

Also, the report from our study is an indication that the school age children and teenagers are the population at risk of schistosomiasis. Control measures should, therefore, be targeted more on this at-risk group in the study area.

\section{Acknowledgments}

The authors would like to express their appreciation to Apojola community for given consents prior to sample collection

\section{Funding}

This research did not receive any specific grant from funding agencies in the public, commercial, or not-forprofit sectors

\section{Competing interests}

The authors declare that they have no competing interests.

\section{References}

1. Yamey G, "The world's most neglected diseases," $B M J$. 2002; 325: 176-177

2. Zhang Y, MacArthur C, Mubila L, Baker S. Control of neglected tropical diseases needs a long-term commitment. BMC Medicine. 2010; 8:67

3. WHO, "Investing to overcome the global impact of Neglected Tropical Diseases. Third WHO report on Neglected Tropical Diseases 2015, Geneva: Author; 2015; 191 
4. Steinmann P, Keiser J, Bos R, Tanner M, Utzinger J. Schistosomiasis and water resources development: systematic review, meta-analysis, and estimates of people at risk. Lancet Infect Dis. 2006; 6 (7): 411-25

5. Adenowo AF, Oyinloye BE, Ogunyinka BI, Kappo AP. Impact of human schistosomiasis in sub-Saharan Africa. BrazJ Infect Dis. 2015; 19 (2):196-205

6. Hotez PJ, Kamath A. Neglected tropical diseases in Sub-Saharan Africa: review of their prevalence, distribution and disease burden. PLoS Negl Trop Dis. 2009; 3:e412, 7. Sulyman MA, Fagbenro-Beyioku AF, Mafe MA, Omotola BD, Adedoyin JA, Akande DO. Schistosoma haematobium and concurrent parasitic infections in school aged children. Niger J Parasitol. 2009; 30(2):79-85

8. Fana SA, Ekejindu IM, Nnamah AK. Urinary schistosomiais among school children in Argungu, Kebbi State. Niger J Parasitol. 2009; 30(2):152-155

9. Akinboye DO, Ajisebutu JU, Fawole O, Agbolade OM, Akinboye OM, Amosu AM, Atulomah NOS, Awodele O, Oduola O, Owodunni BM, Rebecca SN, Falade M, Emem O. Urinary Schistosomiasis: Water contact frequency and infectivity among secondary school students in Ibadan, Nigeria," Niger J Parasitol. 2011;32(1):129-134

10. Ofoezie IE. Human health and sustainable water resources development in Nigeria: Schistosomiasis in artificial lakes. Natural Resources Forum. 2002; 26:150-160

11. Okpala HO, Agwu E, Agba MI, Chimezie OR, Nwobu GO, Ohihoin AA. A survey of the prevalence of Schistosomiasis among pupils in Apata and Laranto areas in Jos, Plateau State. Online J Health Allied Scs. 2004; 1:1-4

12. Stothard JR, French MD, Simba Khamis I, Basa'ñez MG, Rollinson D. The epidemiology and control of urinary schistosomiais and soil-transmitted helminthiasis in schoolchildren on Unguja Island, Zanzibar. Trans R Soc Trop Med Hyg. 2009; 103: 1031-1044

13. Cheesbrough M. District laboratory practice in tropical countries, part 1. $2^{\text {nd }}$ ed. Cambridge: Cambridge University Press; 2005.

14. Duwa MR, Oyeyi TI, Bassey SE. Prevalence and intensity of urinary schistosomiasis among primary school pupils in Minjibir local government area of Kano State, Nigeria. Bayero J Pure Appl Sci. 2009;2:75-8.

15. Babatunde TA, Asaolu SO, Sowemimo OA. Urinary schistosomiasis among preschool and school aged children in two pre-urban communities in Southwest Nigeria J Parasitol Vector Biol. 2013; 5(7):96-101.

16. AmehIG. Urogenital schistosomiasis and proteinuria in
Kebbi State, Nigeria," Niger J Parasitol. 2008; 29 (2): 88 91

17. Oniya MO, Olofintoye LK. The prevalence of urinary schistosomiasis in two endemic Local Government Areas of Ondo State. Niger J Parasitol. 2008; 30:147 - 151

18. Yirenya-Tawiah DR, Annang T, Otchere J, Bentum D, Edoh D, Amoah C, Bosompem KM. Urinary Schistosomiasis among Adults in the Volta Basin of Ghana: Prevalence, Knowledge and Practices. Trop Med Parasitol. 2011; 34:1-16

19. Kimbi HK, Wepnje GB, Anchang-Kimbi J, Tonga C, Ayukenchengamba B, Njabi C, Nono LK, Nyabeyeu HN, Lehman LG. Active Case Detection and Prevalence of Urinary Schistosomiasis and Malaria in Pupils of Kotto Barombi, Southwest Cameroon Using the CyScope ${ }^{\circledR}$ Fluorescence Microscope. IJTDH. 2015; 8(1):1-12

20. Houmsou RS, Agere, H, Wama BE, Bingbeng JB, Amuta EU, and Kela SL, "Urinary Schistosomiasis among Children in Murbai and Surbai Communities of Ardo-Kola Local Government Area, Taraba State, Nigeria," Trop Med Parasitol. 2016, doi:10.1155/2016/9831265

21. Chidozie EU, Danijan SY. Urinary schistosomiasis, epidemiological survey of Urinary schistosomiais among children in selected schools: a preliminary study in Minna, Niger State, Nigeria. Afr. J. Biotechnol. 2008; 7(16): $277-36$

22. Ekwunife CA, Agbor VO, Ozumba AN, Eneanya CI, Ukaga CN. Prevalence of urinary schistosomiasis in Iyede-Ame community and environ in Ndokwa East local government area, Delta State, Nigeria. Book of Abstracts of Parasitology and Public Health Society of Nigeria. 2008; 32:22

23. World Health Organization, Report of the WHO Informal Consultation on "Schistosomiasis Control," WHO/ CDS/CPC/SIP/99.2. 1998. World Health Organization, Geneva.

24. Oluwasogo OA, Fagbemi OB. Prevalence and risk factors of Schistosoma haematobium infections among primary school children in Igbokuta Village, Ikorodu North Local Government, Lagos State. J Nurs Health Sci, 2013; 2 (6) 62-68

25. Augusto G, Nala R, Casmo V, Sabonete A, Mapaco L, Monteiro J. Geographic distribution and prevalence of schistosomiasis and soil-transmitted helminths among school children in Mozambique," Am J of Trop Med Hyg. 2009; 81(5):799- 803

26. Geleta S, Alemu A, Getie S, Mekonnen Z, Erko B. 
Prevalence of urinary schistosomiasis and associated risk factors among Abobo Primary School children in Gambella Regional State, Southwestern Ethiopia: a cross sectional study. Parasit Vectors. 2015; 8 (1):1106-1114.

27. Mbah M, Useh MF. The relationship between urinary schistosomiasis and the prevailing socio-economic factors of a rural community in Cameroun. Nigerian Journal of Parasitology. 2008 29(1): 5 - 10

28. Chipeta MG, Ngwira B, Kazembe LN. Analysis of schistosomiasis haematobium infection prevalence and intensity in Chikhwawa, Malawi: An application of a twopart model. PLoS Negl Trop Dis. 2013; 7(3): e2131. DOI: 10.1371/journal.pntd.0002131

29. Sama MT, Oyono E, Ratard RC. High risk behaviours and schistosomiasis infection in Kumba, South-West Province, Cameroon. Int. J. Environ. Res. Public Health. 2007; 4(2):101-105.

30. Yapi YG, Briet OJT, Diabate S, Vounatsou P, Akodo $\mathrm{E}$, Tanner M, Teuscher T. Rice irrigation and schistosomiasis in savannah and forest areas of Co^ te d'Ivoire. Acta Trop. 2005; 93: 201-21.

31. Bala AY, Ladan MU, Mainasara M. Prevalence and intensity of urinary schistosomiasis in Abarma village, Gusau, Nigeria: a preliminary investigation. Science World Journal. 2012; 7(2)

32. Amuta EU, Houmsou RS, "Prevalence, intensity of infection and risk factors of urinary schistosomiais in pre- school and school aged children in Guma Local Government Area, Nigeria. Asian Pac J Trop Med. 2014; 34-39 33. Dawaki S, Al-Mekhlafi HM, Ithoi I, Ibrahim J, Abdulsalam AM, Ahmed A, Sady H, Atroosh WM, Al-Areeqi MA, Elyana FN, Nasr NA, Surin J. Prevalence and risk factors of schistosomiasis among Hausa communities in Kano State, Nigeria. Rev Inst Med Trop Sao Paulo. 2016; 58:54

34. Uneke C, Oyibo P, Ugwuoru C, Nwanokwai A, Iloegbunam R. Urinary Schistosomiasis among School Age Children in Ebonyi State, Nigeria. The Internet Journal of Laboratory Medicine. 2007; 2 (1)

35. Mahmond AAF. Trematodes (Schistosomiasis) and other Flukes, in: Mendel, G. L., Bennett, J. E., Dolin, R. (Eds.), Mendel, Douglas and Bennett Principles and practice of Infection Diseases. Churchill Livingston, New York 2000; 2950-295

36. Secor WE, del Cerral H, dos Reis MG, Ramos EA, Zimon AE, Matos EP, Reis EA, Do Carmo TM, Hirayama K, David RA, JDavid JR, Harn DA. Association of hepatosplenic schistosomiais with HLA - DOB1* 0201 Journal of Infectious Disease, 1996; 174:1331-1135. PubMed. 37. Otuneme OG, Akinkuade FO, Obebe OO, Usiobeigbe OS, Faloye TG, Olasebikan AS, Akinleye WA, Koku OD. A study on the prevalence of Schistosoma Haematobium and Schistosoma Intercalatum in a rural community of Ogun State, Nigeria," South East Asia Journal of Public Health. 2014; 4 (1); 67-71 